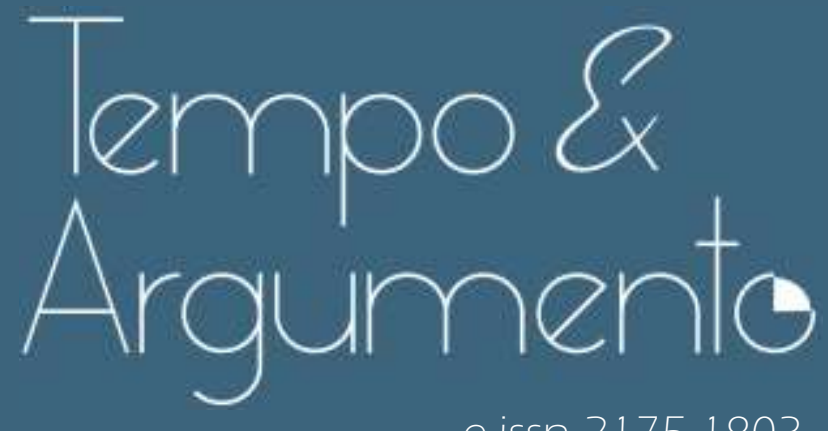

e-issn 2175-1803

\title{
Ensino de História: temporalidade, pós-verdade e verdade poética
}

- Marcelo de Mello Rangel

Doutor em História Social da Cultura pela Pontificia Universidade Católica do Rio de Janeiro (PUC-Rio). Professor dos Programas de Pós-Graduação em História e em Filosofia da Universidade Federal de Ouro Preto (UFOP).

Mariana, MG - BRASIL

lattes.cnpq.br/2419520606896435

mmellorangel@yahoo.com.br

(D) orcid.org/0000-0002-5822-4969

Para citar este artigo:

RANGEL, Marcelo de Mello. Ensino de História: temporalidade, pós-verdade e

verdade poética. Tempo e Argumento, Florianópolis, e0 1 10, 2021. Número especial.

do http://dx.doi.org/10.5965/21751803ne2021 e0 110 


\title{
Ensino de História: temporalidade, pós-verdade e verdade poética ${ }^{1}$
}

\begin{abstract}
Resumo
Ouvindo alunos da graduação nos 4 estágios supervisionados que temos no departamento de História da Universidade Federal de Ouro Preto (UFOP), percebi que 2 temas têm aparecido e retornado com frequência: a) certo desinteresse, ao menos inicial, dos estudantes do ensino básico pelo passado, pela história e pelo ensino de História, especialmente no que diz respeito a um modo específico de relacionamento com passados: o epistemológico-crítico-pragmático; e, também, b) certo questionamento dos alunos (às vezes até mais enérgico/violento) de determinadas interpretações propostas pelos professores. Temos pensado sobre esses desafios ao longo de nossos cursos, de modo que este artigo aborda parte de nossas discussões sobre as questões da temporalidade e da pós-verdade, especialmente naquilo que diz respeito a certo desinteresse pela história e pelo ensino de História. E, por fim, tematizamos um comportamento epistemológico a partir do qual seria possível certo reencantamento da história e do ensino de História, o que denomino verdade poética.
\end{abstract}

Palavras-chave: temporalidade; pós-verdade; verdade poética.

\section{History teaching: temporality, post-truth and poetic truth}

\begin{abstract}
Listening to undergraduate students in the 4 supervised internships available at the Department of History of the Federal University of Ouro Preto (UFOP), I have noticed that 2 themes frequently appear and reappear: a) a certain lack of interest, at least initially, of basic education students in the past, in history, and in History teaching, especially with regard to a specific way of relating to the past times: the epistemological-critical-pragmatic; and also b) a certain questioning by the students (sometimes even more energetic/violent) of certain interpretations proposed by teachers. We have been thinking about these challenges throughout our courses, so this article addresses part of our discussions on the themes of temporality and posttruth, especially concerning a certain lack of interest in history and the History teaching. And, finally, we thematize an epistemological behavior through which a certain re-enchantment of history and History teaching could be possible, what I call poetic truth.
\end{abstract}

Keywords: temporality; post-truth; poetic truth.

\footnotetext{
Agradeço a Rogério Rosa pelo convite para participar do "IV Seminário Internacional História do Tempo Presente” (UDESC, 2021), no qual apresentei a conferência que originou este artigo.
} 
Temporalidade, história e ensino de história

Nosso encontro teve aquela qualidade de doçura que continua, que perdura por toda a vida: mesmo que você nunca mais fale com a

pessoa, nunca mais the veja o rosto, sempre pode voltar, em seu coração, àquele momento em que vocês estiveram juntos e ser renovada - é uma solidariedade profunda. bell hooks (2017, p. 82)

Posso não saber agora que risco corro, mas sei que, como presença no mundo, corro risco. É que o risco é um ingrediente necessário à mobilidade sem a qual não há cultura nem história. Daí a importância de uma educação

que, em lugar de procurar negar o risco, estimule mulheres e homens a assumi-lo.

Paulo Freire (2000, p.30)

Parte significativa das(os) minhas/meus alunas(os) das disciplinas de estágio supervisionado, do curso de História da Universidade Federal de Ouro Preto (UFOP), têm relatado um desinteresse, ao menos imediato, pelas aulas de história no ensino básico. Elas(eles) têm percebido certa apatia, indiferença e mesmo antipatia (distanciamento, deslocamento) quando as professoras(es) do ensino básico propõem o tema da aula e apresentam determinados contextos e personagens. Boa parte das alunas(os) do ensino fundamental e médio permanecem atentos aos seus celulares, conversam entre si, mostrando certo tédio e até contrariedade. E comentam: "O que vamos fazer depois da aula?", "Para que serve isso?", "Isso não tem nada a ver com a gente!", "A professora é legal, mas essa matéria é chata!”.

Temos pensado juntos nas aulas de estágio supervisionado e algumas considerações e explicações têm aparecido mais frequentemente: as alunas(os) do ensino básico têm se mostrado impacientes, preferem ficar a maior parte do tempo na internet, nas redes sociais; parte das professoras(es) também não seriam tão pacientes e insistiriam em determinada posição mais central e até 
autoritária que já não seria adequada ou possível. As (Os) próprias professoras(es) estão esgotadas(os), precisam se deslocar entre escolas muitas vezes distantes, enfrentando longos engarrafamentos, violência e não são reconhecidos nem bem-remunerados. O mercado estaria mais interessado em profissões que não se relacionariam tanto com a história, pelo menos não tão aparentemente. Pais e mães estariam preocupados com o ensino de história, de humanidades em geral, pois seriam "ideológicos" e provocariam seus filhos, de algum modo, no sentido de certa relação mais desinteressada e mesmo cética em relação às aulas de história, e isso para não falarmos do tratamento negativo que a história (e as humanidades em geral) tem recebido a partir de certo avanço quer da extrema direita quer de certa técnica, lógica e ritmo produtivista (do que também podemos chamar de neoliberalismo e seu empreendedorismo de si) mais imediatista e egoísta. Enfim, temos uma série de razões que nos ajudam a compreender esse desinteresse e mesmo antipatia consideráveis pelo ensino de história (pelas humanidades); no entanto, temos nos dedicado a pensá-lo, ao menos inicialmente, a partir de um problema específico: a temporalidade e, mais especialmente, a temporalidade contemporânea.

Nossa compreensão é a de que haveria algo na temporalidade contemporânea que estaria tornando o ensino de história, ao menos num primeiro momento, desinteressante, e que estaria na base de certa impaciência de parte das alunas(os) do ensino básico e também na universidade (especialmente em outros cursos nos quais temos disciplinas dedicadas à história) no que se refere à tematização e discussão cuidadosa de boa parte dos contextos e personagens apresentados pelas(os) professoras(es), tendo em vista a possibilidade de uma relação mais íntima entre presente e passados, especialmente com o objetivo de nos relacionarmos mais razoável e criativamente com os problemas e possibilidades próprios ao nosso mundo (modo de relação epistemológico-crítico-pragmático)².

Comecemos pela questão da consciência histórica, e o que percebemos, então, é que todos nós nos mobilizamos, necessariamente, entre passados e

\footnotetext{
${ }^{2}$ Ver: ABREU, Marcelo Santos de; RANGEL, Marcelo de Mello. Memória, cultura histórica e ensino de história. História e Cultura, [s.l.], v. 4, p. 7-24, 2015.
} 
futuros, e mais, que diante de determinados impasses e possibilidades propostos pelo nosso mundo tenderíamos a nos recolocar mais conscientemente entre passados e futuros com o objetivo de lidar de maneira ao menos mais razoável com transformações sociais, políticas, culturais e econômicas ${ }^{3}$. De modo que a história (o tempo) é marcada pela necessidade da transformação e cada um de nós experimenta contextos críticos também, e especialmente, a partir da

\footnotetext{
Sobre a consciência histórica, Rüsen explicita que: "São as situações genéricas e elementares da vida prática dos homens (experiências e interpretações do tempo) que constituem o que conhecemos como consciência histórica. Elas são fenômenos comuns ao pensamento histórico tanto no modo científico quanto em geral, tal como operado por todo e qualquer homem, e geram determinados resultados cognitivos" (RÜSEN, 2001, p. 54).

"Trata-se de 'processos de pensamento e de formação estruturadores de consciência', 'que geralmente encontram-se 'por trás' dos conteúdos e que habitualmente ficam velados ao aprendiz', de 'atos mentais determinantes do comportamento, que subjazem à lida com a História'” (RÜSEN, 2011, p. 42).

"O caráter processual do aprendizado histórico nas narrativas da(s) história(s) pode ser descrito como segue: o estímulo e a força pulsional do aprendizado histórico encontra-se nas necessidades de orientação de indivíduos agentes e pacientes, necessidades que surgem para tais indivíduos quando de desconcertantes experiências temporais. O aprendizado histórico pode ser posto em andamento, portanto, somente a partir de experiências de ações relevantes do presente. Essas carências de orientação são transformadas então em perspectivas (questionadoras) com respeito ao passado, que apreendem o potencial experiencial da memória histórica" (RÜSEN, 2011, p. 44).

“... a história é enraizada nas necessidades sociais para orientar a vida dentro da estrutura do tempo" (RÜSEN, 2011, p. 25).

Isso que Rüsen chama de consciência histórica, essa (re)tematização necessária, mais imediata e também consciente, de passados com o objetivo de nos relacionarmos mais adequadamente com as transformações próprias à realidade efetiva (Wirklichkeit), também constitui o pensamento de Koselleck. Para Koselleck, nos relacionamos necessariamente com passados e futuros, com o objetivo de nos reorganizarmos junto a determinada realidade efetiva, "Em outras palavras: todas as histórias foram constituídas pelas experiências vividas e pelas expectativas das pessoas que atuam ou que sofrem" (KOSELLECK, 2006, p. 306).

"As condições de possibilidade da história real são, ao mesmo tempo, as condições de possibilidade do seu conhecimento. Esperança e recordação, ou mais genericamente, expectativa e experiência (...) são constitutivas, ao mesmo tempo, da história e de seu conhecimento, e certamente o fazem mostrando e produzindo a relação interna entre passado e futuro, hoje e amanhã" (KOSELLECK, 2006, p. 308).

"Com isso chego à minha tese: experiência e expectativa são duas categorias adequadas para nos ocuparmos com o tempo histórico, pois elas entrelaçam passado e futuro. São adequadas também para se tentar descobrir o tempo histórico, pois, enriquecidas em seu conteúdo, elas dirigem as ações concretas no movimento social e político. [...] A história concreta amadurece em meio a determinadas experiências e determinadas expectativas. [...] Como categorias, eles (os conceitos de experiência e expectativa) fornecem as determinações formais que permitem que o nosso conhecimento histórico decifre essa execução. Eles (experiência e expectativa) remetem à temporalidade do homem, e com isto, de certa forma meta-historicamente, à temporalidade da história" (KOSELLECK, 2006, p. 308-309).

Ressaltamos, ainda, que essa compreensão temporal de Koselleck, assentada na relação entre experiência (passados) e expectativa (futuros), está diretamente relacionada ao problema da temporalidade em Heidegger, especialmente no que tange à compreensão heideggeriana de que o Dasein (cada um de nós) é originariamente indeterminado, se mobilizando entre o mundo que é o seu ("aí") e o "poder-ser" que também somos. Sendo justamente essa mobilidade entre "aí" e "poder-ser" que está na base da temporalização ou diferenciação do Dasein e da história (tempo). Nesse sentido, ver o quinto capítulo, §§ 72-77, de Ser e Tempo.
} 
reorganização mais consciente de nossas relações com passados e futuros, com tradições mais ou menos disponíveis e com determinadas expectativas, projetos. A partir dessa compreensão da história (do tempo) e de nós mesmos como parte significativa do próprio movimento de reorganização, de diferenciação da história, chegamos a uma percepção importante para a nossa atividade profissional, para o pensamento histórico, para o exercício historiográfico e para o ensino de história: todas(os) nós precisamos e nos relacionamos de forma mais ou menos consciente com passados e futuros, especialmente em contextos mais críticos ${ }^{4}$. Enfim, se, por um lado, teríamos uma crise da disciplina história e do ensino de história, também podemos trabalhar, por outro, com uma hipótese que me parece bem convincente (e mesmo animadora): a de que a despeito das nossas coordenadas espaço-temporais, de quando e de onde nos encontramos, precisamos e precisaremos de passados e futuros para nos mobilizarmos, ou ainda, sempre haverá, de alguma forma, interesse por espaços nos quais passados e futuros são tratados mais consciente/reflexivamente, pela disciplina história, pelo ensino de história...

No entanto, essa percepção não é e não pode ser apenas tranquilizadora, pois, se bem precisamos de passados e futuros, da história e do ensino de história para nos reposicionarmos, para participarmos mais efetivamente do movimento de diferenciação da história (tempo), não podemos simplesmente negar que temos uma crise significativa da nossa atividade, que parte da sociedade e das nossas(os) alunas(os) têm manifestado um desinteresse considerável em relação às nossas pesquisas e aulas.

Nesse caso, apesar de certo conforto no que tange à dimensão e importância de nossa atividade profissional, da pesquisa e do ensino de história, é importante continuar pensando detidamente, construir um diagnóstico cuidadoso e minucioso desse desinteresse que temos observado e experimentado, em relação ao qual temos reagido muitas vezes com impaciência e até pessimismo. E, aqui, gostaria de propor certa leitura da temporalidade

\footnotetext{
4 “A consciência histórica mistura 'ser' e 'dever' em uma narração significativa que refere acontecimentos passados com o objetivo de fazer inteligível o presente, e conferir uma perspectiva futura a essa atividade atual. Desta forma, a consciência histórica traz uma contribuição essencial à consciência ético-moral" (RÜSEN, 2011, p. 57).
} 
contemporânea com o objetivo de pensar e compreender ao menos parte desse desinteresse pela história e pelo ensino de história hoje.

O que temos de maneira mais geral, ao menos em relação ao problema da temporalidade, é que há algo próprio à temporalidade contemporânea que também tem tornado possível esse desinteresse pela história, pelo ensino de história, pela tematização e discussão mais cuidadosa de passados. Eu diria que há certa apatia e mesmo antipatia pelo(s) passado(s) ao menos no que diz respeito a um modo de relação com o passado que está na base da nossa atividade (da nossa disciplina): o modo epistemológico-crítico-pragmático. O que temos, assim, é algo complexo: por um lado certo desinteresse e mesmo antipatia pela tematização mais cuidadosa (científica) da história, e, por outro lado, um crescimento do interesse pelo conhecimento de determinados contextos e personagens em outros espaços da cultura histórica como o cinema, teatro, música, jogos eletrônicos, e isso mais a partir de outro modo de relação com passados: o estético. Ou ainda, com base em certo desejo de simplesmente conhecer mais e atualizar, assim, certa necessidade mais geral de ter mais experiências ${ }^{5}$.

A nossa percepção é a de que se, por um lado, nos relacionamos, necessariamente, quer de forma mais imediata quer mais consciente ou teoricamente, com passados e futuros, por outro lado, a própria relação com passados e futuros é marcada e de alguma forma determinada pelos horizontes ou contextos históricos nos quais nos encontramos. Se sempre nos relacionamos com passados e futuros, essa relação também é constituída por certo grau de especificidade dependendo do nosso horizonte, da nossa sociedade.

\footnotetext{
Sempre nos relacionamos com passados e futuros a partir de ambos os modos: o epistemológico-crítico-pragmático e o estético. O que ocorre é que há temporalidades e contextos nos quais podemos ter uma generalização e mesmo hipostasia no que diz respeito a um acesso mais epistemológico-crítico-pragmático ou mais estético. É justamente essa questão que está na base da tematização que Gumbrecht faz do que chama de "cultura de sentido" e "cultura de presença": "A presença e o sentido, porém, sempre aparecem juntos e sempre estão em tensão. É impossível compatibilizá-las ou reuni-las numa estrutura fenomênica 'bem equilibrada'” (GUMBRECHT, 2010, p. 134).

Ver, também: ABREU, Marcelo Santos de; CUNHA, Nara Rúbia de Carvalho. Cultura de história, história pública e ensino de história: a investigação e formação de professores de história. História Hoje, [s.l.], v. 8, p. 111-134, 2019.
} 
Diferentemente da modernidade, por exemplo, experimentamos, hoje, uma relação com o tempo, com passados e futuros (claro, de uma forma mais geral, entre outras possíveis e dependendo dos grupos e contextos mais específicos ${ }^{6}$ ), marcada pelo que podemos chamar de uma dupla-redução: a redução da confiança em passados mais disponíveis e também no futuro, o qual tem sido experimentado como um horizonte que tenderia a aprofundar determinados dramas contemporâneos? ${ }^{7}$ O que temos, assim, é uma temporalidade constituída por certo afastamento (especialmente no que tange ao modo de relação epistemológico-crítico-pragmático) em relação ao(s) passado(s), compreendidos, ao menos de maneira mais geral, como ultrapassado(s), obsoleto(s) e, portanto, inadequado(s) no que diz respeito a

\footnotetext{
${ }^{6}$ Ver: GUIMARÃES, Géssica; RAUTER, Luisa. Ativismo, movimentos sociais e politização do tempo: possibilidades dos femininos no Brasil contemporâneo. In.: GUIMARÃES, Géssica; PINHA, Daniel; RANGEL, Marcelo de Mello (org.). Diante da crise: teoria, história da historiografia e ensino de história hoje. Vitória: Milfontes, 2021.

"Desde muitas décadas ninguém realmente leva a sério personagens da história como modelo de atuação. Vou dar um exemplo literário: muitos entre vocês terão lido o romance maravilhoso do grande realista francês Stendhal, de 1831, referindo-se à revolução burguesa na França de 1830. Há um jovem protagonista, Julien Sorel. Toda a ambição da vida desse personagem é ser igual a Napoleão, ele quer ser uma cópia de Napoleão. Eu acho que isso para nós, na prática, já não existe. Podemos admirar o papa Joseph Ratzinger, talvez possamos admirar o presidente Lula - para termos dois protagonistas bem diferentes -, podemos ainda admirar Tiradentes. Mas a forma de expressarmos isso seria ser um fã ou um admirador de Lula, não querer copiar um personagem e tomá-lo como um paradigma histórico para a atuação em nosso próprio tempo" (GUMBRECHT, 2011, p. 28).

"[...] já não estamos em um cronótopo historicista. Nosso futuro não continua sendo um futuro aberto de possibilidades. O futuro de hoje é cada vez mais ameaçador, um risco que assumimos com seguros. Um exemplo disso foi o enorme sucesso do texto de Al Gore, que dizia que tínhamos no máximo cinco anos antes de liberarmos as partes mais agressivas da ameaça ecológica. Que se não conseguíssemos baixar, reduzir drasticamente certos índices de poluição, em cinco anos já não haveria solução. Este não é um discurso de um futuro aberto de possibilidades. O discurso econômico de hoje é um discurso, nesse momento, preocupado com a sobrevivência. [...] não somos nós mais que vamos em direção ao futuro, é ele que de modo ambíguo vem ao nosso encontro" (GUMBRECHT, 2011, p. 39).

"[...] acho interessante que antigamente o modelo historicista de identificar regularidade de transformação histórica existia como base em previsões. Identificando regularidades de transformação histórica costumava-se projetar cenários no futuro e então ter uma orientação para a ação [...] hoje acho que nenhum político sério faz isto: analisar a história, fazer a projeção e logo atuar assim. Por exemplo, existem todas aquelas previsões ecológicas, sabe-se que o exvice-presidente dos Estados Unidos, Al Gore, recebeu o prêmio Nobel por uma previsão sobre o futuro ecológico do planeta. Mas hoje, no momento em que as previsões são publicadas, publicam-se também contraprevisões" (GUMBRECHT, 2011, p. 28-9).

"Um filósofo alemão de quem gosto muito, Niklas Luhmann, que inventou certa filosofia dos sistemas, tem uma boa fórmula. Ele nos diz que no passado faziam-se previsões apenas com a análise do passado. Hoje, em vez disso, compramos seguros para nos protegermos de um futuro indesejado. Não temos ideia de como será o futuro, não fazemos previsões, mas compramos seguros caso o futuro seja indesejável, negativo para nós, para nos proteger" (GUMBRECHT, 2011, p. 29).
} 
possíveis respostas a questões e possibilidades mais contemporâneas. Uma percepção que se constitui em grande parte em razão do tipo de relação que estabelecemos com a tecnologia, a qual tem feito o passado parecer tão diferente, atrasado e obsoleto ${ }^{8}$.

$\mathrm{O}(\mathrm{s})$ passado(s), seus costumes, personagens, moda, artefatos, ideias e instituições vão parecendo cada vez mais antiquados e mesmo atrasados. Gosto de pensar aqui a partir de uma metáfora de Koselleck, o Sattelzeit, "tempo de sela", que aponta para uma espécie de aceleração da aceleração do tempo, para a percepção temporal de que cada presente tende a se diferenciar e a parecer ainda mais distinto do seu passado imediato do que esse foi e pareceu ser em relação ao que o antecedeu.

Em relação ao futuro, também temos uma percepção social generalizada, ampla, de que é provável que venhamos a experimentar uma espécie de aprofundamento de determinados dramas que já estão disponíveis: ecológicos, sanitários, político-diplomáticos, econômicos... o que se aproximaria de certa orientação (atmosfera, Stimmung) pessimista e distópica?.

Assim, o que temos é uma dupla-redução no que tange à confiança em passados e futuros, um desinteresse (apatia) e mesmo, em determinados contextos, certa antipatia em relação a passados e futuros os quais são, como vimos mais acima, tão importantes ao nosso posicionamento e relação com o tempo, à reorganização e diferenciação da história (tempo) ${ }^{10}$.

\footnotetext{
8 "Todas essas percepções eram agravadas pela sensação de aceleração, seja efetivamente existente ou pressentida. Todos pareciam correr o risco de se tornarem obsoletos, de ficaram por fora" (ARAUJO; PEREIRA, 2019, p. 172).

9 "Dis é um prefixo latino muito comum que remete à ideia de dualidade, divisão em duas partes, separação, movimento em vários sentidos, afastamento, cessação, negação, falta, intensidade. Ele encerra a ideia de dificuldade e de duplicidade. Mas há também um prefixo grego dys que indica dualidade, dificuldade e mau estado. Topos, por sua vez, é um radical que significa lugar, de modo que defino distopia, mais livremente, como um deslugar, um lugar e sua negação, um lugar cindido ou ainda um lugar em deslocamento. Ou seja, temos um lugar deslocado, impróprio, fora do lugar. No plano filosófico, a distopia representa a resistência ao humanismo diante de realidades sempre hostis, das quais, aparentemente, não é possível escapar" (BENTIVOGLIO, 2019, p. 21).

10 No que diz respeito à importância de uma relação mais intensa e confiante em passados e futuros menos disponíveis para a reestruturação e diferenciação do presente ver: BENJAMIN, Walter. Sobre o conceito de história. In:: LÖWY, Michael (org.). Walter Benjamin: aviso de incêndio. Uma leitura das teses "Sobre o conceito de história". São Paulo: Boitempo, 2005; BEVERNAGE, Berber. History, memory, and state-sponsored violence: time and justice. New York: Routledge, 2012; DERRIDA, Jacques. Espectros de Marx. O estado da dívida, o trabalho do luto e a nova
} 
Chegamos, então, a uma descrição razoavelmente suficiente do que seria a temporalidade em geral e a temporalidade contemporânea, e, desse modo, à própria compreensão da relação entre a temporalidade contemporânea e certo desinteresse, apatia e mesmo antipatia atual pela história e pelo ensino de história.

Para sermos mais claros, há uma apatia e uma antipatia de boa parte das crianças, adolescentes e adultos pelo passado e pelo futuro. Boa parte de nós se encontra, por outro lado, excessivamente próximos a nós mesmos, buscando a produção incessante de prazer ${ }^{11}$.

O que proponho é algo que poderíamos chamar de circular: quanto mais desconfiamos tão significativamente de que passados e futuros podem nos ajudar a nos relacionarmos epistemológico-crítico-pragmaticamente com

Internacional. Rio de Janeiro: Relume-Dumará, 1994; DOMANSKA, Ewa. The material presence of the past. History and Theory, [s.l.], v. 45, p. 337-348, 2006; GUMBRECHT, Hans Ulrich. Produção de presença: o que o sentido não consegue transmitir. Rio de Janeiro: Contraponto: Ed. PUCRio, 2010; HEIDEGGER, Martin. Ser e tempo. Petrópolis: Vozes; Bragança Paulista: Editora Universitária São Francisco, 2008 (especialmente o quinto capítulo, §§ 72-77); KLEINBERG, Ethan. Presence in absentia. In: GHOSH, Ranjan; KLEINBERG, Ethan (eds.). Presence: philosophy, history, and cultural theory for the twenty-first century. Ithaca; London: Cornell University Press, 2013; RANGEL, Marcelo de Mello. Da ternura com o passado: história e pensamento histórico na filosofia contemporânea. Rio de Janeiro: Editora Via Verita, 2019a e RANGEL, Marcelo de Mello. A história e o impossível: Walter Benjamin e Derrida. Rio de Janeiro: Ape’Ku, 2020.

1 É essa compreensão que está na base da reflexão de Gumbrecht sobre o que chama de broad present, especialmente a partir de noções como simultaneidade, estagnação, fascinação e tecnologia. "Essa disponibilidade de meios para a satisfação fácil e imediata tornou-se uma regra e estende-se inclusive ao passado. Mais do que nunca podemos evocar momentos do passado por meio de arquivos e produtos da indústria da nostalgia, que transformou o nosso presente em uma presença dilatada de simultaneidades e desacelerou nossa impressão do ritmo do tempo histórico. [...] o individualismo extremo tornou-se, assim, um fenômeno de massa do nosso tempo. Seu preço reside no fato de que a disponibilidade fácil da realidade está vinculada à expectativa há muito internalizada de nos pormos permanentemente à disposição" (GUMBRECHT, 2012, p. 84).

Essa percepção de que nos organizamos hoje muito mais a partir da necessidade de ampliarmos o nosso prazer também está na base da crítica de Heidegger à técnica: “... uma região se desenvolve na exploração de fornecer carvão e minérios. O subsolo passa a se desencobrir, como reservatório de carvão, o chão, como jazidas de minério. Era diferente o campo que o camponês outrora lavrara, quando lavrar ainda significava cuidar e tratar. O trabalho camponês não provoca e desafia o solo agrícola. [...] hoje em dia, uma outra posição também absorveu a lavra do campo, a saber, a posição que dis-põe da natureza. E dela dis-põe, no sentido de uma exploração. A agricultura tornou-se indústria motorizada de alimentação. Dis-põe-se o ar a fornecer azoto, o solo a fornecer minério, como, por exemplo, urânio, o urânio a fornecer energia atômica; esta pode, então, ser desintegrada para a destruição da guerra ou para fins pacíficos. [...] trata-se da forma de descobrimento da técnica que o desafia (o homem) a explorar a natureza, tomando-a por objeto de pesquisa até que o objeto desapareça no não-objeto da disponibilidade. [...] a técnica moderna não se reduz a um mero fazer do homem. [...] está em causa o poder que o leva a dis-por do real, como dis-ponibilidade" (HEIDEGGER, 2006, p. 19-23). 
questões e possibilidades colocadas pelo nosso mundo, mais nos afastamos das dimensões que podem dar suporte efetivo a uma relação mais razoável e criativa com o nosso contexto ou horizonte: os próprios passados e futuros. Quanto mais nos afastamos de uma relação epistemológico-crítico-pragmática mais cuidadosa e confiante em passados e futuros, mais vamos perdendo as companhias ideais à experiência do tempo e nos empobrecendo, nos distanciando dos afetos, experiências, dramas, orientações e sonhos que podem dar suporte e estimular uma relação epistemológico-crítico-criativa com a história (com o tempo, especialmente no que diz respeito à participação em seu movimento de transformação, de diferenciação).

Assim, empobrecidos, temos nos dedicado à estratégia de nos relacionarmos excessivamente conosco mesmos, com o objetivo de ir ampliando significativa e freneticamente o nosso prazer. E, por fim, quanto mais nos envolvemos com esse modo hipostasiado de relação conosco mesmos, mais nos afastamos da possibilidade de uma relação epistemológico-crítico-pragmática, atenta, cuidadosa, confiante em relação a passados e futuros ${ }^{12}$. O ritmo mesmo próprio a esse modo de relação epistemológico-crítico-pragmático, um ritmo mais lento, contínuo e meticuloso, vai se tornando (parecendo) penoso, e os afetos adequados a esse modo de relação (epistemológico-crítico-pragmático) e ao seu ritmo vão sendo questionados, afugentados, como observou Benjamin; afetos como a paciência, tenacidade, constância, modéstia, atenção, certo ceticismo (crítico) ou desconfiança, ira/fúria (“justa ira”) e o amor ${ }^{13}$.

\footnotetext{
12 Ver: RANGEL, Marcelo de Mello. Temporalidade e felicidade hoje: uma relação possível entre o pensamento histórico, a democracia e a experiência da felicidade. Artefilosofia, [s.l.], v.25, p. 5267, 2018.

13 Sobre esse ritmo próprio a certa relação epistemológico-crítico-pragmática com passados e futuros ver: BENJAMIN, Walter. Experiência e pobreza. In: WALTER BENJAMIN: obras escolhidas: magia e técnica, arte e política: ensaios sobre literatura e história da cultura. São Paulo: Brasiliense, 1994; BENJAMIN, Walter. O narrador. Considerações sobre a obra de Nikolai Leskov. In: Walter Benjamin: obras escolhidas: magia e técnica, arte e política. Ensaios sobre literatura e história da cultura. São Paulo: Brasiliense, 1994a; BENJAMIN, Walter. Sobre o conceito de história. In: LÖWY, Michael (org.). Walter Benjamin: aviso de incêndio. Uma leitura das teses "Sobre o conceito de história". São Paulo: Boitempo, 2005 e RANGEL, Marcelo de Mello. Temporalidade e felicidade hoje: uma relação possível entre o pensamento histórico, a democracia e a experiência da felicidade. Artefilosofia, [s.l.], v.25, p. 52-67, 2018. No que se refere a certa economia afetiva própria a essa relação epistemológico-crítico-pragmática com passados e futuros, o que também estou chamando de virtude afetivo-epistêmica, ver: RANGEL, Marcelo de Mello. História e Stimmung a partir de Walter Benjamin: sobre algumas possibilidades ético-políticas da historiografia. Cadernos Walter Benjamin, [s.l.], v.17, p. 165-178,
} 
Desse modo, vamos compreendendo melhor essa experiência contemporânea de desinteresse, apatia e mesmo de antipatia em relação a passados e futuros especialmente no que diz respeito ao modo de relação que constitui a nossa atividade, a disciplina história e o ensino de história, o modo epistemológico-crítico-pragmático. Nossas(os) alunas(os) insistem, assim, em nos perguntar: "Para que conhecer algo tão diferente, que não se relaciona com a gente?".

\section{Pós-verdade, história e ensino de história}

Ainda temos enfrentado como professoras e professores em geral e, em nosso caso, de história, um problema adicional no que tange à perda de certo protagonismo. Temos acompanhado o desinteresse e mesmo agressões verbais e físicas no âmbito da escola, por exemplo, em razão de determinadas interpretações, compreensões e posições. E aqui passamos de certo desinteresse para uma postura mais claramente reativa. E o que torna possível essa reatividade?

Em primeiro lugar, não se trata aqui de uma reclamação ou contestação, de um protesto ou nostalgia em relação a tempos nos quais a ciência e a posição do professor, a sua palavra e comportamentos, seriam mais protagonistas ou teriam certa reverência. Pelo contrário, e como veremos mais adiante, compreendemos e temos nos dedicado ao que pode ser considerado um

\footnotetext{
2016; RANGEL, Marcelo de Mello. Entrevista Marcelo de Mello Rangel. Ensaios Filosóficos, [s.l.], v. XVI, p. 119-139, 2017; RANGEL, Marcelo de Mello. Rehistoricização da história, melancolia e ódio. In: BENTIVOGLIO, Julio; CARVALHO, Augusto de (org.). Walter Benjamin: testemunho e melancolia. Serra: Milfontes, 2019b; RANGEL, Marcelo de Mello. Giro ético-político, verdade e felicidade. In: CARVALHO, Augusto de; RANGEL, Marcelo de Mello (org.). História \& filosofia: problemas ético-políticos. Vitória: Milfontes, 2020a; RANGEL, Marcelo de Mello. Resistência, ódio e amor! In: AMITRANO, Georgia; HADDOCK-LOBO, Rafael; RANGEL, Marcelo de Mello (org.). Rosas e pensamentos outros. Rio de Janeiro: Ape'Ku, $2020 \mathrm{~b}$.

Segundo Benjamin: "Elas (as coisas finas e espirituais, os afetos) estão vivas nessa luta como confiança, como coragem, como humor, como astúcia, como tenacidade..." (BENJAMIN, 2005, p. 58 - Tese IV). E de acordo com Paulo Freire: "Como não se pode lutar, por faltar coragem, vontade, rebeldia, se não se tem amanhã, se não se tem esperança” (FREIRE, 2000, p. 47).

E no que tange à "justa ira": "Não junto a minha voz à dos que, falando em paz, pedem aos oprimidos, aos esfarrapados do mundo, a sua resignação. Minha voz tem outra semântica, tem outra música. Falo da resistência, da indignação, da "justa ira" dos traídos e dos enganados. Do seu direito e do seu dever de rebelar-se contra as transgressões éticas de que são vítimas cada vez mais sofridas." (FREIRE, 1997, p. 113).
} 
aprofundamento da tensão entre perspectivas as mais variadas no que diz respeito à ciência e ao ensino, à própria dinâmica da sala de aula. Trata-se apenas de explicitar, nesse primeiro momento, certa perda do protagonismo da ciência, do professor, que não vem acompanhada, nesse caso, de uma reorganização mais democratizante do espaço científico e da sala de aula, mas, sim, de uma negação da ciência, da educação em geral.

Essa perda de protagonismo da ciência, da própria posição do professor, está diretamente ligada ou pode ser mais bem compreendida a partir da tematização do comportamento que é o da pós-verdade.

A pós-verdade pode ser pensada como um comportamento epistemológico com base no qual não há qualquer responsabilidade em relação ao que é dito, e nem um esforço de distanciamento, e, por conseguinte, de alguma diferenciação entre os desejos menos tematizados de quem pensa e se expressa e os enunciados que constitui, ou ainda, não há qualquer exercício de objetividade. E aqui ressaltamos que estamos trabalhando com uma noção de objetividade que é a um só tempo simples e ampla, capaz de acolher outras compreensões e que funciona, inclusive, como condição de possibilidade para toda e qualquer objetividade, a saber: o que é objetivo se desdobra necessariamente de um deslizamento e diferenciação razoável entre o dito e certa posição mais imediata (não tematizada) do sujeito enunciador.

O que é dito a partir desse comportamento que é o da pós-verdade se confunde plenamente com quem diz, especialmente no que tange a afetos e desejos menos conscientemente elaborados e (re)organizados. Do mesmo modo, não há qualquer demora que separe o ato de enunciação e a sua repercussão. A repercussão é imediata, o que equivale a dizer que não temos tempo para a dúvida, para o (auto) questionamento, (auto) crítica, reorganização e complexificação de enunciados. A pós-verdade pode ser compreendida, assim, como um comportamento epistemológico determinado pelo par egoísmo/hedonismo, pelo desejo de que não haja qualquer negação ou descontinuidade entre determinado sujeito e realidade (Wirklichkeit). Um comportamento epistemológico que acaba tendo efeitos ainda mais graves e devastadores em sociedades com uma história escravocrata como a nossa, 
marcadas por uma espécie de hipostasia ou paroxismo de uma lógica e ética que seria mais geral, a do senhor-escravo.

O que constatamos, assim, é um esquema autoritário com base no qual temos o questionamento de todo e qualquer espaço e exercício mais cuidadoso, dialogal, tenso e plural (democratizante) no que diz respeito à constituição e reconstituição de enunciados objetivos (no sentido que propomos mais acima: o de certo deslizamento e diferenciação entre o dito e a posição mais imediata do sujeito enunciador). É exatamente nesse contexto que temos o questionamento significativo da universidade, da ciência, da educação, da historiografia, do ensino de história, enfim, das humanidades em geral e de certo papel mais protagonista da(o) professora(or), da(o) cientista. Nesse caso, diferentemente de uma reorganização da ciência, da educação e da aula num sentido democratizante, o que temos é um comportamento que avança no sentido da negação da ciência, da educação, da aula, tendo em vista que, de acordo com esse comportamento que é o da pós-verdade, cada um de nós aparece como o único lugar autoritário- a partir do qual enunciados, compreensões e interpretações se tornam possíveis.

Retornamos, desse modo, ao que já havíamos mencionado mais acima, à constatação e compreensão mais cuidadosa de que se a ciência e a educação em geral têm sofrido certo questionamento e desinteresse, temos uma dificuldade ainda mais considerável no que tange à supressão desse desinteresse e antipatia em relação à história e ao ensino de história.

Nesse caso, se trata de uma aproximação perigosa entre:

1- determinado desinteresse pela história e pelo ensino de história que pode ser parcialmente compreendido a partir da análise da temporalidade contemporânea. Ou seja, um desinteresse provocado por certa percepção mais geral de que o passado está muito distante de nós, portanto teria pouco ou nada a nos dizer, e o futuro, por sua vez, seria um espaço no qual experimentaríamos, muito provavelmente, um aprofundamento de dramas contemporâneos. 
2- um desinteresse e mesmo antipatia pela ciência, pela educação e pela figura do professor em geral (e também pela história e pelo ensino de história), provocado pela ampliação desse comportamento epistemológico que é o da pós-verdade.

\section{História, ensino de história e verdade poética}

Com base nesse diagnóstico, tenho elaborado um duplo questionamento, um à pós-verdade e outro a certa tendência de propormos o paradigma correspondentista (verdade como adequação), pelo menos tão imediatamente e a despeito da crítica que tem sido cuidadosamente constituída ao longo dos séculos XX e XXI, como sendo a proposta epistemológica que salvaguardaria a possibilidade da objetividade e do reencantamento do interesse pela ciência, pela educação, pela história e pelo ensino de história. O que gostaria de propor é que o paradigma correspondentista representa ou torna possível um tipo específico de objetividade, um entre outros, e não o único, e que ele não seria um argumento suficiente a certo reencantamento da história e do ensino de história hoje.

Proponho, a seguir, certa crítica ao paradigma correspondentista e à sua compreensão de objetividade e, em seguida, outro modo de objetividade também possível com base no comportamento epistemológico-ético-político que chamo de verdade poética, ou ainda e mais sinteticamente, o que podemos pensar como uma composição e recomposição cuidadosa e recorrente de enunciados e interpretações possíveis no interior de determinada assembleia diversificada, a partir de outras e outros. A posição aqui é a de que esse comportamento epistemológico-ético-político seria suficiente a algum reencantamento da história e do ensino de história, um reencantamento a um só tempo rigoroso e ético-politicamente orientado, o qual seria capaz de convocar e reunir parte das crianças, jovens e adultos em nome de outros aspectos e composições sociais possíveis.

Desse modo, o objetivo, a partir de agora, é explicitar os três motivos que considero mais relevantes no que diz respeito a uma crítica possível a essa 
defesa contemporânea, pelo menos tão imediata, do comportamento epistemológico correspondentista.

Em primeiro lugar, precisamos lembrar que o espaço a partir do qual esse comportamento epistemológico se generalizou foi justamente o de determinada hiperespecialização, constituída por um conjunto limitado de cientistas e professores, nesse caso mais cientistas do que professores e muito mais homens do que mulheres, e, em geral, provenientes de classes ou grupos privilegiados ${ }^{14}$. Trata-se, portanto, de um comportamento epistemológico que se ampliou especialmente a partir do século XIX e com base na atividade científica de homens privilegiados- europeus ou europeizados-que teriam o treinamento e o acesso às condições necessárias à constituição de certa atenção teóricometodológico-empírica com base na qual seria possível a organização de enunciados adequados à realidade, ou seja, compreendidos, a partir desse espaço, como objetivos (verdadeiros).

O que temos, assim, é o próprio risco de, com base numa defesa mais rápida e menos crítica do paradigma correspondentista, retomarmos ou tornamos possível a retomada de certo comportamento epistemológico que pode ou tende a vir acompanhado do perigo (e/ou da pretensão) de certo elitismo ou exclusivismo no que tange à elaboração de perspectivas e modos de ser, de temas e objetos que seriam mais propriamente válidos ${ }^{15}$. Ou ainda, corremos o

\footnotetext{
${ }^{14}$ E no que diz respeito à história mais especificamente: "Durante o século XIX, quando os historiadores definiram sua disciplina, eles começaram a perder de vista um importante princípio, a saber, que a história é enraizada nas necessidades sociais para orientar a vida dentro da estrutura do tempo. O entendimento histórico é guiado fundamentalmente pelos interesses humanos básicos: assim sendo, é direcionado para uma audiência e tem um papel importante na cultura política da sociedade dos historiadores. Como os historiadores do século XIX se esforçaram para tornar a história uma ciência, este público foi esquecido ou redefinido para incluir apenas um pequeno grupo de profissionais especialistas treinados. [...] a 'cientifização' da história acarretou um estreitamento consciente de perspectiva, um limitador dos propósitos e das finalidades da história" (RÜSEN, 2011, p. 25). Ver, também: WHITE, Hayden. The practical past. Evanston, Illinois: Northwestern University Press, 2014.

${ }^{15}$ Ver: DUSSEL, Enrique. Filosofia da libertação: crítica à ideologia da exclusão. São Paulo: Paulus Editora, 1995; HADDOCK-LOBO, Rafael. Os fantasmas da colônia: notas de desconstrução e filosofia popular brasileira. Rio de Janeiro: Ape'Ku, 2020; MIGNOLO, Walter. Histórias locais/projetos globais: colonialidade, saberes subalternos e pensamento liminar. Belo Horizonte: Editora da UFMG, 2019; MORAES, Marcelo. Democracias espectrais: por uma desconstrução da colonialidade. Rio de Janeiro: Nau, 2020; QUIJANO, Aníbal. Colonialidad del poder y clasificación social. Journal of World-Systems, [s.l.], v.11, n.2, p.342-86, 2000; SANTOS, Boaventura de Sousa. O fim do império cognitivo: a afirmação das epistemologias do Sul. Belo Horizonte: Autêntica, 2019; SANTOS, Boaventura de Sousa; NUNES, João Arriscado; MENESES, Maria Paula. Opening up the Canon of knowledge and recognition of difference. In: SANTOS,
} 
risco, assim, de certa recolonização de espaços como a escola e a universidade que têm se democratizado, claro, não sem grande esforço e mais lentamente do que boa parte de nós gostaria ${ }^{16}$.

O segundo motivo da minha crítica à defesa mais imediata e mesmo inflexível (exclusiva) do paradigma correspondentista é que o argumento da objetividade (nesse caso pela via de uma adaequatio mais clássica) não seria suficiente, ao menos não no que tange ao nosso contexto, a certo reencantamento e supressão de parte do desinteresse pela história e pelo ensino de história hoje. Uma boa parte da sociedade tem se relacionado com passados a partir de um interesse mais estético, com o objetivo de ampliar experiências e o que podemos chamar de prazer. Portanto, boa parte da nossa sociedade não está exatamente interessada em se relacionar com passados a partir da garantia da objetividade (nesse caso correspondentista), mas sim com base em certo esteticismo e hedonismo. Desse modo, não tem sido suficiente argumentar apenas em termos de objetividade (correspondência, adequação), por exemplo, junto a um conjunto de crianças, adolescentes e adultos que estão mais preocupados em experimentar outros contextos e ampliar indefinidamente seu prazer.

Não temos tempo suficiente e também não é o que pretendemos aqui, mas sublinhamos que trabalhamos, a partir desse diagnóstico, com base em certa tradição que tem pensado a importância da mobilização também estética,

Boaventura de Sousa (ed.). Another knowledge is possible: beyond Northern epistemologies. London: Verso, 2007; SIMAS, Luiz Antonio; RUFINO, Luiz. Flecha no tempo. Rio de Janeiro: Mórula, 2019 e SPIVAK, Gayatri Chakravorty. Pode o subalterno falar? Belo Horizonte: Editora da UFMG, 2014.

${ }^{16}$ Sobre relações possíveis entre história, ensino de história e (re)democratização no/do Brasil, ver: GUIMARÃES, Géssica; SOUSA, Francisco Gouvea de. Desmonte ou reconstrução da universidade: entre o capital e a democratização. Revista Hydra, [s.l.], v.4, p. 103-131, 2019; OLIVEIRA, Rodrigo Perez; PINHA, Daniel; RANGEL, Marcelo de Mello. Teoria, historiografia e ensino de história em tempos de crise democrática. Transversos, [s.l.], n. 18, p. 6-16, abr. 2020; RANGEL, Marcelo de Mello. A história e o impossível: Walter Benjamin e Derrida. Rio de Janeiro: Ape'Ku, 2020; PINHA, Daniel. Formação e corrosão democrática no Brasil do tempo presente: desafios à história da historiografia e ao ensino de história. In: GUIMARÃES, Géssica; PINHA, Daniel; RANGEL, Marcelo de Mello (org.). Diante da crise: teoria, história da historiografia e ensino de história hoje. Vitória: Milfontes, 2021; RODRIGUES, Thamara de Oliveira; RANGEL, Marcelo de Mello. Temporalidade e crise: sobre a (im)possibilidade do futuro e da política no Brasil e no mundo contemporâneo. Maracanan, [s.l.], n. 18, p. 66-82, jan./jun. 2018 e SOUSA, Francisco Gouvea de. Ensino e cidadania, redemocratização e descolonização. In: GUIMARÃES, Géssica; PINHA, Daniel; RANGEL, Marcelo de Mello (org.). Diante da crise: teoria, história da historiografia e ensino de história hoje. Vitória: Milfontes, 2021. 
especialmente em contextos como o nosso, para que se torne possível, a partir de estratégias estéticas, a ampliação da experiência e a provocação de certa desarmonia no aparato intelectivo (entendimento, imaginação e pensamento em termos kantianos), com base na qual possamos ter certa reformulação e reorganização conceitual, logo a objetivação e superação de determinados preconceitos e posições até então menos tematizadas ${ }^{17}$.

O terceiro motivo pelo qual critico essa defesa mais imediata do paradigma correspondentista - e sua compreensão de objetividade - é que a ciência está, em geral, comprometida com determinado mundo mais sedimentado, se mobilizando a partir do que esse mundo torna possível, das suas orientações, percepções, interesses mais gerais, de modo que a correspondência ou não de determinado enunciado a algo diante de nós está francamente relacionada e é, portanto, medida por aquilo que já é visível. Ou seja, para que possamos conferir o caráter de verdade de determinada sentença com base no paradigma correspondentista, já precisamos contar com certa percepção ou conhecimento prévio de determinado objeto, tema, o qual regula de certa forma o que pode e vai sendo dito sobre ele mesmo ${ }^{18}$.

\footnotetext{
17 Ver: DELEUZE, Gilles. Empirismo e subjetividade: ensaio sobre a natureza humana segundo Hume. São Paulo: Editora 34, 2001; DELEUZE, Gilles. Lógica do sentido. São Paulo: Perspectiva, 1998; LYOTARD, Jean-François. Peregrinações: lei, forma, acontecimento. São Paulo: Estação Liberdade, 2000; RANCIĖRE, Jacques. A partilha do sensível: estética e política. São Paulo: Exo experimental: Editora 34, 2009; RANCIĖRE, Jacques. O desentendimento: política e filosofia. São Paulo: Editora 34, 2018 e GUMBRECHT, Hans Ulrich. Produção de presença. O que o sentido não consegue transmitir. Rio de Janeiro: Contraponto: Ed. PUC-Rio, 2010.

18 Para uma crítica da fenomenologia ao paradigma correspondentista (adequação):

"Uma enunciação é verdadeira, quando aquilo a que ela visa e diz está em conformidade com a coisa sobre a qual se pronuncia. Também nesse caso dizemos: está de acordo. O que, porém, está agora de acordo não é a coisa, mas antes a proposição.

O verdadeiro, seja uma coisa verdadeira ou uma proposição verdadeira, é aquilo que está de acordo, o que concorda. Ser verdadeiro e verdade significam aqui 'estar de acordo'; e isto de duas maneiras: por um lado, a consciência entre uma coisa e o que dela previamente se presume, e, por outro lado, a concordância entre o que é visado pela enunciação e a coisa.

Este duplo caráter de concordância traz à luz a definição tradicional da essência da verdade: veritas est adaequatio rei et intellectus. Isto pode significar: a verdade é a adequação da coisa com o conhecimento. Mas pode se entender também assim: a verdade é a adequação do conhecimento com a coisa. Ordinariamente, a mencionada definição é apenas apresentada pela fórmula: Veritas est adaequatio intellectus ad rem. Contudo, a verdade assim entendida, a verdade proposicional, só é possível quando fundada na verdade da coisa, a adaequatio rei ad intellectum. Estas duas concepções da essência da veritas significam um conformar-se com... e pensam, com isto, a verdade como conformidade" (HEIDEGGER, 2008, p. 191-192).

"A veritas enquanto adaequatio rei (creandae) ad intellectum (divinum) garante a veritas enquanto adaequatio intellectus (humani) ad rem (creatam). Veritas significa por toda parte e essencialmente a convenientia e a concordância dos entes entre si que, por sua vez, se fundam
} 
Esse modo de comportamento da ciência não é equivocado, pelo contrário, é mais propriamente comum (ou ontológico), pois já nos encontramos dentro de um mundo específico que nos orienta e torna possível os comportamentos teóricos e práticos em geral, colocando, apresentando, assim, aquilo que precisa ser investigado, com base em certa visibilidade mínima (ou prévia, pré-predicativa num sentido husserliano). Assim, essa característica mais geral da ciência não é exatamente um problema a ser superado a qualquer preço, sendo muito mais uma característica que marca a ciência e também a educação em todo e qualquer contexto. No entanto, a ciência e a educação também podem se comprometer com algo mais do que seria o aperfeiçoamento de determinadas compreensões que de algum modo já temos acerca do que já é visível. Compreendo e defendo a ideia de que as ciências e a educação, a história e o ensino de história, também podem se atentar àquilo que não está mais propriamente visível, que está obscuro e/ou despontando, ou seja, também se preocupar e participar do movimento de aparecimento de outras e outros e

sobre a concordância das criaturas com o criador, 'harmonia' determinada pela ordem da criação" (HEIDEGGER, 2008, p. 193).

"Assim, pode parecer que esta concepção da essência da verdade seja independente da interpretação relativa à essência do ser de todo o ente: esta última inclui, entretanto, necessariamente uma interpretação correspondente da essência do homem como sujeito que é portador e realizador do intellectus. Assim, a fórmula da essência da verdade (veritas est adaequatio intellectus et rel) adquire, para cada um e imediatamente, uma evidente validez" (HEIDEGGER, 2008, p. 193).

"Esta aparição da coisa, enquanto cobre (mede) um âmbito contraposto, realiza-se no interior de um espaço aberto, cuja abertura nunca é criada primeiramente pela apresentação, mas é sempre investida e assumida por ela como campo de relação. A ligação do enunciado representacional com a coisa é a realização daquela relação que se realiza, originariamente e cada vez, como o desencadear de um comportamento. Todo o comportamento, porém, se caracteriza pelo fato de, estabelecido no interior do aberto, se manter sempre e a cada vez junto àquilo que é manifesto enquanto tal. Somente aquilo que, assim, no sentido estrito da palavra, está manifesto foi experimentado precocemente pelo pensamento ocidental como ‘aquilo que está presente’ e já, desde há muito tempo, é chamado 'ente’” (HEIDEGGER, 2008, p. 196).

"Na medida em que a enunciação obedece a tal ordem, ela se conforma ao ente. O dizer que se submete a tal ordem é conforme, correto (verdadeiro). O que assim é dito é o que é conforme, correto (verdadeiro).

O enunciado recebe sua conformidade da abertura do comportamento. Pois é somente através dela que algo manifesto pode se tornar, de maneira geral, a medida diretora de uma apresentação adequada (...) Isto quer dizer: o comportamento mesmo deve receber antecipadamente o dom prévio dessa medida diretora de toda apresentação" (HEIDEGGER, 2008, p. 197).

"A essência da verdade desvelou-se como liberdade. Essa liberdade é o deixar-se ek-sistente que descobre o ente. Todo comportamento aberto se movimenta no deixar-se do ente e se relaciona com este ou aquele ente particular. A liberdade já colocou previamente o comportamento em harmonia com o ente na totalidade, na medida em que ela é o abandono ao desvelamento do ente na totalidade e enquanto tal” (HEIDEGGER, 2008, p. 204). 
tomar parte, no limite, da própria reorganização ou reconstituição da realidade efetiva (Wirklichkeit) na qual nos mobilizamos ${ }^{19}$.

Assim, chegamos ao problema da verdade poética, comportamento epistemológico muito distinto da pós-verdade e também do paradigma correspondentista. O que está em questão a partir da verdade poética é justamente o esforço no que diz respeito a essa relação com o que não está mais propriamente visível, tratando-se da tematização do que está obscurecido, periferizado, vulnerabilizado e/ou despontando20. Mas como seria possível, nesse caso, uma ciência ou uma educação que também se dedicasse ao que não está exatamente visível?

Não temos tempo suficiente para tematizar mais cuidadosamente esse momento ou possibilidade da ciência e da educação, da história e do ensino de história: a de se relacionar com o que não está exatamente visível. Mas ainda podemos tornar essa reflexão e proposta um pouco mais concreta.

A condição de possibilidade ou certo método básico para esse comportamento epistemológico, que é o da verdade poética, é justamente a oscilação entre espaços os mais distintos (o que também podemos chamar de hiperempiria), e, assim, o contato direto, mais franco e recorrente, com perspectivas, modos de ser e saberes diversos. De modo que é justamente a partir dessa hiperempiria, desse modo (franco e recorrente) de relação com a diferença que seria possível certo afastamento de si mesmo (do que já é mais comum), abrindo espaço para outras e outros e tornando possível a constituição de certa sensibilidade mais acurada no que tange à percepção do que está mais

\footnotetext{
19 Ver: BEVERNAGE, Berber. History, memory, and state-sponsored violence: time and justice. New York: Routledge, 2012; DERRIDA, Jacques. O olho da universidade. São Paulo: Estação Liberdade, 1999; DERRIDA, Jacques. A universidade sem condições. São Paulo: Estação Liberdade, 2003; DERRIDA, Jacques. Vadios. Coimbra: Palimage, 2009; DOMANSKA, Ewa; SIMON, Zoltán Boldizsár; TAMM, Marek. Anthropocenic historical knowledge: promises and pitfalls (no prelo); KLEINBERG, Ethan. Haunting history. for a deconstructive approach to the past. Stanford: Stanford University Press, 2017; RIBEIRO, Renato Janine. A universidade e a vida atual: Fellini não via filmes. São Paulo: Editora da Universidade de São Paulo, 2014; RODRIGUES, Thamara de Oliveira. Outros modos de pensar e sonhar: a experiência onírica em Reinhart Koselleck, Ailton Krenak e Davi Kopenawa. Revista de Teoria da História, [s.l.], v. 23, p. 156-177, 2020; RODRIGUES, Thamara de Oliveira. Theory of history and history of historiography: openings for unconventional histories. História da Historiografia, [s.l.], v. 12, n. 29, p. 96-123, 2019.

${ }^{20}$ Para o problema da vulnerabilidade, ver BUTLER, Judith. Vida precária: os poderes do luto e da violência. Belo Horizonte: Autêntica, 2019. (especialmente p. 157-182).
} 
obscurecido, vulnerabilizado e/ou despontando. A nossa compreensão aqui é a de que é justamente esse posicionamento mais franco e atento em meio à diversidade que torna possível ou continua/intensifica certa tensão (democratizante) e a própria constituição de um conjunto de afetos adequados à percepção do que difere e à insistência nesse comportamento que é o do acolhimento do que não está mais propriamente visível, afetos como o amor, a modéstia, paciência (atenção, escuta) e certa fúria (indignação), os quais constituem o que gostaria de chamar de virtudes afetivo-epistêmicas.

Desse modo, a verdade poética se constitui a partir da disponibilidade (e esforço) de estar recorrentemente entre outras e outros ouvindo e sendo ouvido, organizando e reorganizando cuidadosa e responsavelmente interpretações possíveis. Interpretações que são objetivas, mas não exatamente porque se aproximam mais ou menos do real, mas porque se constituem a partir do que podemos chamar de uma assembleia marcada pela diversidade, por perspectivas e saberes diversos, com base em uma relação mais complexa com a realidade efetiva (Wirklichkeit). Sendo exatamente a partir dessa tensão que temos a possibilidade e mesmo a necessidade de uma atenção teórica, metodológica, empírica e crítica (intersubjetiva) significativa, pois precisamos cuidar do que é fundamental quando se trata de estar em um espaço como esse marcado pela diferença (ao menos a partir de certo posicionamento democratizante): de uma audição e consideração paciente em relação ao que cada uma e cada um explicita e, também, ao que pensamos, para que seja possível a constituição comunitária de determinadas compreensões compartilháveis, as quais, nesse caso, são organizadas com base no deslizamento entre o dito e certa posição mais imediata do sujeito enunciador, sendo, portanto, objetivas.

O que gostaria de sublinhar, antes ainda de terminarmos, é exatamente o caráter epistemológico-ético-político desse comportamento científico que é o da verdade poética, pois: a- é marcado por certa objetividade (deslizamento entre o dito e a posição imediata do sujeito enunciador), b- porque torna possível a constituição e retenção de certa afetividade própria a uma atenção teórica, metodológica, empírica e crítica (intersubjetiva) expressiva, e isto, c- com base 
ou acompanhando/intensificando o que chamo de democratização ou ainda a partir da participação efetiva de outras e outros na constituição de enunciados, compreensões compartilháveis e relações que têm o poder de reorganizar a realidade efetiva (Wirklichkeit).

\section{Referências}

ABREU, Marcelo Santos de; CUNHA, Nara Rúbia de Carvalho. Cultura de história, história pública e ensino de história: a investigação e formação de professores de história. História Hoje, [s.l.], v. 8, p. 111-134, 2019.

ABREU, Marcelo Santos de; RANGEL, Marcelo de Mello. Memória, cultura histórica e ensino de história. História e Cultura, v. 4, p. 7-24, 2015.

ALBUQUERQUE JÚNIOR, Durval Muniz. Fazer defeitos nas memórias: para que servem a escrita e o ensino da história? In.: GONÇALVES, Márcia de Almeida; ROCHA, Helenice; REZNIK, Luís; Ana Maria Monteiro (org.). Qual o valor da História hoje? Rio de Janeiro: Editora da FGV, p. 21-39, 2012. p. 21-39.

ARAÚJO, Helena Maria Marques. Produzindo narrativas e memórias decoloniais no ensino de história. In.: GUIMARÃES, Géssica; PINHA, Daniel; RANGEL, Marcelo de Mello (org.). Diante da crise: teoria, história da historiografia e ensino de história hoje. Vitória: Milfontes, 2021.

ARAUJO, Valdei Lopes de; PEREIRA, Mateus. Atualismo 1.0. como a ideia de atualização mudou o século XXI. Vitória: Milfontes; Mariana: Editora da SBTHH, 2019.

ARAUJO, Valdei Lopes de; RANGEL, Marcelo de Mello. Apresentação; teoria e história da historiografia: do giro linguístico ao giro ético-político. História da Historiografia, Ouro Preto, v.8, n. 17, p. 318-332, abr. 2015.

BENJAMIN, Walter. Experiência e pobreza. In.: Walter Benjamin. Obras escolhidas. Magia e técnica, arte e política. Ensaios sobre literatura e história da cultura. São Paulo: Brasiliense, 1994a.

BENJAMIN, Walter. O narrador. Considerações sobre a obra de Nikolai Leskov. In.: Walter Benjamin: obras escolhidas: magia e técnica, arte e política. Ensaios sobre literatura e história da cultura. São Paulo: Brasiliense, 1994b.

BENJAMIN, Walter. Sobre o conceito de história. In.: LÖWY, Michael (org.). Walter Benjamin: aviso de incêndio: uma leitura das teses "Sobre o conceito de história”. São Paulo: Boitempo, 2005.

BENTIVOGLIO, Julio. História \& distopia. Vitória: Milfontes, 2019.

BEVERNAGE, Berber. History, Memory, and State-Sponsored Violence: Time and Justice. New York: Routledge, 2012. 
BUTLER, Judith. Vida precária: os poderes do luto e da violência. Belo Horizonte: Autêntica, 2019.

CARVALHO, Augusto de; RANGEL, Marcelo de Mello. História e filosofia e outros mundos possíveis. In.: CARVALHO, Augusto de; RANGEL, Marcelo de Mello (org.). História \& Filosofia: problemas ético-políticos. Vitória: Milfontes, 2020.

CEZAR, Temístocles. O que fabrica o historiador quando faz história, hoje? Ensaio sobre a crença na história (Brasil séculos XIX-XXI). Revista de Antropologia, São Paulo, v. 61, p. 78-95, 2018.

DELEUZE, Gilles. Empirismo e subjetividade. Ensaio sobre a natureza humana segundo Hume. São Paulo: Editora 34, 2001.

DELEUZE, Gilles. Lógica do sentido. São Paulo: Perspectiva, 1998.

DERRIDA, Jacques. A universidade sem condições. São Paulo: Estação Liberdade, 2003.

DERRIDA, Jacques. Espectros de Marx. O estado da dívida, o trabalho do luto e a nova Internacional. Rio de Janeiro: Relume-Dumará, 1994.

DERRIDA, Jacques. O olho da universidade. São Paulo: Estação Liberdade, 1999.

DERRIDA, Jacques. Vadios. Coimbra: Palimage, 2009.

DOMANSKA, Ewa; SIMON, Zoltán Boldizsár; TAMM, Marek. Anthropocenic historical knowledge: promises and pitfalls (no prelo).

DOMANSKA, Ewa. The Material Presence of the Past. History and Theory, v. 45, p. 337-348, 2006.

DUSSEL, Enrique. Filosofia da libertação: crítica à ideologia da exclusão. São Paulo: Paulus Editora, 1995.

FREIRE, Paulo. Pedagogia da autonomia. Rio de Janeiro: Paz \& Terra, 1997.

FREIRE, Paulo. Pedagogia da indignação: cartas pedagógicas e outros escritos. São Paulo: Editora UNESP, 2000.

GUIMARÃES, Géssica; PINHA, Daniel; RANGEL, Marcelo de Mello (Org.). Diante da crise. Teoria, história da historiografia e ensino de história hoje. Vitória:

Milfontes, 2021.

GUIMARÃES, Géssica; RAUTER, Luisa. Ativismo, movimentos sociais e politização do tempo: possibilidades dos femininos no Brasil contemporâneo. In.:

GUIMARÃES, Géssica; PINHA, Daniel; RANGEL, Marcelo de Mello (org.). Diante da 
crise: teoria, história da historiografia e ensino de história hoje. Vitória: Milfontes, 2021.

GUIMARÃES, Géssica; SOUSA, Francisco Gouvea de. Desmonte ou reconstrução da universidade: entre o capital e a democratização. Revista Hydra, [s.l.], v.4, p. 103-131, 2019.

GUMBRECHT, Hans Ulrich. Depois de "depois de aprender com a história", o que fazer com o passado agora? In.: ARAUJO, Valdei Lopes de; MOLLO, Helena Miranda; NICOLAZZI, Fernando (org.). Aprender com a história? O passado e o futuro de uma questão. Rio de Janeiro: Editora FGV, 2011.

GUMBRECHT, Hans Ulrich. Graciosidade e estagnação: ensaios escolhidos. Rio de Janeiro: Contraponto: Ed. PUC-Rio, 2012.

GUMBRECHT, Hans Ulrich. Nosso amplo presente: o tempo e a cultura contemporânea. São Paulo: Editora Unesp, 2015.

GUMBRECHT, Hans Ulrich. Produção de presença: o que o sentido não consegue transmitir. Rio de Janeiro: Contraponto: Ed. PUC-Rio, 2010.

HADDOCK-LOBO, Rafael. Os fantasmas da colônia. Notas de desconstrução e filosofia popular brasileira. Rio de Janeiro: Ape’Ku, 2020.

HEIDEGGER, Martin. A essência da verdade (1930). In.: Marcas do Caminho. Petrópolis, RJ: Vozes, 2008a.

HEIDEGGER, Martin. A questão da técnica. In.: Ensaios e Conferências. Petrópolis: Vozes; Bragança Paulista: Editora Universitária São Francisco, 2006.

HEIDEGGER, Martin. Ser e tempo. Petrópolis: Vozes: Bragança Paulista: Editora Universitária São Francisco, 2008b.

HOOKS, bell. Ensinando pensamento crítico: sabedoria prática. São Paulo: Elefante, 2020.

HOOKS, bell. Ensinando a transgredir. a educação como prática da liberdade. São Paulo: Editora WMF Martins Fontes, 2017.

HOOKS, bell. Tudo sobre o amor. novas perspectivas. São Paulo: Elefante, 2020.

KLEINBERG, Ethan. Haunting history: deconstruction and the spirit of revision. History and Theory. 46, p. 113-143, 2007.

KLEINBERG, Ethan. Haunting history. for a deconstructive approach to the past. Stanford: Stanford University Press, 2017. 
KLEINBERG, Ethan. Presence in absentia. In.: GHOSH, Ranjan; KLEINBERG, Ethan (eds.). Presence. Philosophy, History, and Cultural Theory for the Twenty-First Century. Ithaca; London: Cornell University Press, 2013.

KOSELLECK, Reinhart. Futuro passado: contribuição à semântica dos tempos históricos. Rio de Janeiro: Contraponto: Ed. Puc-Rio, 2006.

LYOTARD, Jean-François. Peregrinações: lei, forma, acontecimento. São Paulo: Estação Liberdade, 2000.

MATTOS, Ilmar Rohloff de. "Mas não somente assim!" leitores, autores, aulas como texto e ensino-aprendizagem em História. Tempo, v. 11, n. 21, 2007.

MENDES, Breno. Ensino de história, historiografia e currículo de história. Transversos, v. 18, p. 108-128, 2020.

MIGNOLO, Walter. Histórias locais/projetos globais: colonialidade, saberes subalternos e pensamento liminar. Belo Horizonte: Editora da UFMG, 2019.

MORAES, Marcelo. Democracias espectrais: por uma desconstrução da colonialidade. Rio de Janeiro: Nau, 2020.

MURUCI, Fábio; RANGEL, Marcelo de Mello. Algumas palavras sobre giro éticopolítico e história intelectual. Revista Ágora, vitória, v.21, p. 7-14, 2015.

NICOLAZZI, Fernando. Muito além das virtudes epistêmicas: o historiador público em um mundo não linear. Maracanan, n. 18, p. 18-34, 2018.

OLIVEIRA, Rodrigo Perez; PINHA, Daniel; RANGEL, Marcelo de Mello. Teoria, historiografia e ensino de história em tempos de crise democrática. Transversos, [s.l.], n. 18, p. 6-16, abr. 2020.

PINHA, Daniel. Formação e corrosão democrática no Brasil do tempo presente: desafios à história da historiografia e ao ensino de história. In.: GUIMARÃES, Géssica; PINHA, Daniel; RANGEL, Marcelo de Mello (org.). Diante da crise: teoria, história da historiografia e ensino de história hoje. Vitória: Milfontes, 2021. PINHA, Daniel. O lugar do tempo presente na aula de história: limites e possibilidades. Tempo \& Argumento. Florianópolis, v. 9, n. 20, p. 99-129, 2017.

QUIJANO, Aníbal. Colonialidad del poder y clasificación social. Journal of WorldSystems, v.11, n.2, 2000, p.342-86.

RANCIĖRE, Jacques. A partilha do sensível. Estética e política. São Paulo: Exo experimental org.; Editora 34, 2009.

RANCIĖRE, Jacques. O desentendimento. Política e filosofia. São Paulo: Editora 34, 2018. 
RANGEL, Marcelo de Mello. A história e o impossível. Walter Benjamin e Derrida. Rio de Janeiro: Ape 'Ku, 2020a.

RANGEL, Marcelo de Mello. A urgência do giro ético-político: o giro ético-político na teoria da história e na história da historiografia. Ponta de Lança, v. 13, p. 27 46, 2019a.

RANGEL, Marcelo de Mello. Da ternura com o passado. História e pensamento histórico na filosofia contemporânea. Rio de Janeiro: Editora Via Verita, 2019b.

RANGEL, Marcelo de Mello. Entrevista Marcelo de Mello Rangel. Ensaios Filosóficos, v. XVI, p. 119-139, 2017.

RANGEL, Marcelo de Mello. Giro ético-político, verdade e felicidade. In.: CARVALHO, Augusto de; RANGEL, Marcelo de Mello (org.). História \& Filosofia. Problemas ético-políticos. Vitória: Milfontes, $2020 b$.

RANGEL, Marcelo de Mello. História e Stimmung a partir de Walter Benjamin: Sobre algumas possibilidades ético-políticas da historiografia. Cadernos Walter Benjamin, v.17, p. 165-178, 2016.

RANGEL, Marcelo de Mello. Rehistoricização da história, melancolia e ódio. In.: BENTIVOGLIO, Julio; CARVALHO, Augusto de (org.). Walter Benjamin. Testemunho e melancolia. Serra, Espírito Santo: Milfontes, 2019c.

RANGEL, Marcelo de Mello. Resistência, ódio e amor! In.: AMITRANO, Georgia; HADDOCK-LOBO, Rafael; RANGEL, Marcelo de Mello (org.). Rosas e pensamentos outros. Rio de Janeiro: Ape'Ku, 2020c.

RANGEL, Marcelo de Mello. Temporalidade e felicidade hoje: uma relação possível entre o pensamento histórico, a democracia e a experiência da felicidade. Artefilosofia, v.25, p. 52-67, 2018.

RANGEL, Marcelo de Mello; RODRIGUES, Thamara de Oliveira. Temporalidade e crise: sobre a (im)possibilidade do futuro e da política no Brasil e no mundo contemporâneo. Maracanan, n. 18, pp. 66-82, 2018.

RIBEIRO, Renato Janine. A universidade e a vida atual: Fellini não via filmes. São Paulo: Editora da Universidade de São Paulo, 2014.

RODRIGUES, Thamara de Oliveira. Outros modos de pensar e sonhar: a experiência onírica em Reinhart Koselleck, Ailton Krenak e Davi Kopenawa. Revista de Teoria da História, v. 23, p. 156-177, 2020.

RODRIGUES, Thamara de Oliveira. Theory of history and history of historiography: Openings for unconventional histories. História da Historiografia, v. 12, n. 29, p. 96-123, 2019. 
RÜSEN, JÖRN. Jörn Rüsen e o ensino de história. SCHMIDT, Maria Auxiliadora; BARCA, Isabel; MARTINS, Estevão de Rezende (org.). Curitiba: Ed. UFPR, 2011.

RÜSEN, JÖRN. Razão histórica. Teoria da história: os fundamentos da ciência histórica. Brasília: Editora Universidade de Brasília, 2001.

SANTAELLA, Lucia. A pós-verdade é verdadeira ou falsa? Barueri, SP: Estação das Letras e Cores, 2019.

SANTOS, Boaventura de Sousa. O fim do império cognitivo: a afirmação das epistemologias do Sul. Belo Horizonte: Autêntica, 2019.

SANTOS, Boaventura de Sousa; NUNES, João Arriscado; MENESES, Maria Paula. Opening up the Canon of knowledge and recognition of difference. In.: SANTOS, Boaventura de Sousa (ed.). Another knowledge is possible: beyond Northern epistemologies. London: Verso, 2007.

SIMAS, Luiz Antonio; RUFINO, Luiz. Flecha no tempo. Rio de Janeiro: Mórula, 2019.

SOUSA, Francisco Gouvea de. Ensino e cidadania, redemocratização e descolonização. In.: GUIMARÃES, Géssica; PINHA, Daniel; RANGEL, Marcelo de Mello (org.). Diante da crise: teoria, história da historiografia e ensino de história hoje. Vitória: Milfontes, 2021.

SPIVAK, Gayatri Chakravorty. Pode o subalterno falar? Belo Horizonte: Editora da UFMG, 2014.

WHITE, Hayden. The practical past. Evanston, Illinois: Northwestern University Press, 2014. 